\title{
Enfoques de uma crise: o jornal como fonte de pesquisa histórica
}

\section{Approaches to a crisis: the newspaper as a source of historical research}

\author{
Denise Castilhos de Araujo ${ }^{1}$ \\ Claudia Schemes ${ }^{2}$ \\ Magna Lima Magalhãe ${ }^{3}$
}

\section{RESUMO}

Este artigo tem como objetivo abordar a crise do setor coureiro calçadista a partir de um periódico como fonte histórica. Para tanto, lançamos mão das leituras apresentadas sobre a crise no Jornal $\mathrm{NH}$, diário do município de Novo Hamburgo/RS que possui abrangência regional. Nosso estudo tem por objetivo analisar a abordagem da crise dos anos 90 e sua relação com a produção industrial de calçados no Vale do Rio dos Sinos.

Palavras-chave: Jornal. Setor Coureiro-Calçadista. Vale dos Sinos.

\begin{abstract}
This paper aims to address the crisis in the sector of leather footwear from a journal as a historical source. To this end, we presented the readings on the crisis in NH Journal, Journal of the municipality of Novo Hamburgo / RS which has a regional scope. Our study aims to examine the approach of the crisis of the '90s and its relation to industrial production of shoes in the Vale do Rio dos Sinos.
\end{abstract}

Keywords: Journal. Leather-footwear Industry. Vale dos Sinos.

\footnotetext{
${ }^{1}$ Professora do Instituto de Ciêncas Sociais Aplicadas, pesquisadora do Grupo de Pesquisas Cultura e Memória da Comunidade. Email: deniseca@feevale.br

${ }^{2}$ Doutora em HIstória, professora dos cursos de HIstória e Design de Moda, pesquisadora do Grupo de Estudos em Cultura e Memória da Comunidade. Email: claudias@feevale.br

${ }^{3}$ Doutora em HIstória, professora do curso de HIstória, pesquisadora do Grupo de Estudos em Cultura e Memória da Comunidade.Email: magna@feevale.br (c) (i) (9)

Obra licenciada com uma Licença Creative Commons - Atribuição-Uso Não-ComercialNão a obras derivadas 3.0 Unported.
} 


\section{JORNAL COMO FONTE HISTÓRICA}

Este artigo apresenta algumas reflexões sobre a crise do setor coureiro calçadista, da cidade de Novo Hamburgo, no estado do Rio Grande do Sul a partir de sua apresentação no jornal $\mathrm{NH}$. Lançamos mão do jornal como importante fonte para o trabalho de cunho histórico, posto que a ampliação das abordagens históricas, bem como a possibilidade de reflexões a partir do cotejamento de diferentes fontes contribui de forma significativa para a pesquisa histórica. Sendo assim, os periódicos colaboram com elementos relevantes que nos remetem a discursos e representações sociais.

De acordo com os teóricos da comunicação, especialmente os frankfurtianos ${ }^{4}$, os meios de comunicação de massa determinam a construção da realidade dos seus públicos. Sob esta perspectiva, sem tratar-se de um determinismo, pode-se afirmar que, de alguma forma, a percepção que a comunidade de Novo Hamburgo construiu/constrói do tema a ser investigado é fortemente influenciada pelo jornal referido. Neste sentido, poderíamos dizer que representações ${ }^{5}$ foram construídas acerca da crise do setor coureiro-calçadista no imaginário social do Vale do Rio dos Sinos. Para Baczko (1985, p.310), o imaginário social envolve a construção de imagens oriundas de diferentes agentes sociais, sendo assim o "imaginário social e as representações traduzem as lutas de poder pelo domínio simbólico".

A utilização do jornal como fonte histórica para o historiador vem sendo discutida há muitos anos, pois esta nem sempre foi considerada a fonte mais apropriada para o trabalho historiográfico. Capelato $(1988$, p.13) já dizia que "o periódico, antes considerado fonte suspeita e de pouca importância, já é reconhecido como material de pesquisa valioso para o estudo de uma época".

Entretanto, o documento histórico oriundo da imprensa não pode ser considerado o reflexo da realidade, mas o lugar onde há a representação do real. Ainda segundo Capelato (1988),

\footnotetext{
${ }^{4}$ Estamos nos referindo aos teóricos ligados à Escola de Frankfurt, que surgiu nos anos 20 na Alemanha e que tinha como objetivo realizar um estudo crítico da sociedade em seus vários aspectos, a partir de uma perspectiva marxista renovada.

5 Segundo Chartier (1991), é através das representações contraditórias ou em confronto que os indivíduos ou grupos atribuem significado ao mundo social.
} 
Sua existência é fruto de determinadas práticas sociais de uma época. A produção desse documento pressupõe um ato de poder no qual estão implícitas relações a serem desvendadas. A imprensa age no presente e também no futuro, pois seus produtores engendram imagens da sociedade que serão reproduzidas em outras épocas (CAPELATO, 1988, p. 24,25).

Primamos por uma leitura intensiva do jornal, considerando a circulação, o contexto e os leitores deste (ELMIR, 1995). Os jornais são veículos pelos quais a sociedade produz e veicula modelos e reflexões vigentes em determinada época ${ }^{6}$. A linguagem possibilita determinar valores morais e comportamentais, assim como classificar e justificar grupos sociais, que no entendimento de Bourdieu (2002), seria "um ato de poder". Segundo Orlandi (1990, p.35) "a partir dos jornais, desenvolve-se a construção de um discurso histórico porque cria tradição, passado, e influencia novos acontecimentos".

O jornal, dentro dessa perspectiva, não é apenas fonte de informação, mas, também, fonte histórica, pois,

[...] possui toda uma série de qualidades peculiares, extremamente úteis para a pesquisa histórica. Uma delas é a periodicidade, os jornais constituem-se em verdadeiros arquivos do cotidiano, nos quais podemos acompanhar a memória do dia-a-dia e estabelecer a cronologia dos fatos históricos. Outra é a disposição espacial da informação, que nos permite a inserção do acontecimento histórico dentro de um contexto mais amplo. E outro aspecto singular do material jornalístico é o tipo de censura instantânea e imediata, diferente de outras fontes que poderão ser submetidas a uma tiragem antes de serem arquivadas [...] (ESPIG, 1998, p. 274).

Para além da leitura "intensiva" das palavras lançamos mão da análise qualitativa de conteúdo como forma de categorizar e de sistematizar informações relevantes para o estudo. ${ }^{7}$

Por esta perspectiva, buscamos explorar através do jornal as leituras sobre a crise do setor coureiro-calçadista nos anos 1990 e suas representações veiculadas no Jornal NH, principal veículo de comunicação da cidade de Novo Hamburgo e região.

\footnotetext{
${ }^{6}$ Para Geertz (1989, p.19) não existe documento totalmente imparcial, já que todo relato é carregado de interpretação.

7 Para análise de conteúdo nos respaldamos em BARDIN, Laurence. Análise de conteúdo. Lisboa: Edições 70, 1995; e MORAES, Roque. Análise de conteúdo. Revista Educação, Porto Alegre, n.37, p.732, ano XXI, mar. 1999.
}

Cad. de Pesq. Interdisc. em Ci-s. Hum-s., Florianópolis, v.11, n.99, p. 167-185, jul/dez. 2010 
Conforme os dados do IVC (Instituto Verificador de Circulação), em julho de 2007, o Jornal NH era o maior diário, em termos de assinaturas pagas, do interior do estado do Rio Grande do Sul. A circulação do Jornal NH abrange hoje 52 municípios dos vales do Rio do Sinos, Caí e Paranhana.

O Jornal NH faz parte do Grupo Editorial Sinos ${ }^{8}$, que foi criado em 1957, na cidade de São Leopoldo, por Mário Alberto e Paulo Sérgio Gusmão. A partir de 1960, o grupo se instalou na cidade de Novo Hamburgo, defendendo a ideia de que um jornal deveria participar do processo construtivo de uma sociedade.

Segundo o site do Grupo, seus veículos de comunicação se caracterizam por "diferenciais claramente percebidos, quer em regionalização da cobertura, quer em segmentação editorial, tornando-se fortes e respeitados em suas áreas de atuação". Diz ainda que o "jornalismo comprometido não só com a informação, como também com o desenvolvimento e necessidades das comunidades onde atua, tem sido o maior responsável pelo seu crescimento e sucesso [...]."9

O Jornal $\mathrm{NH}$, com o passar dos anos, ultrapassou os limites do município de Novo Hamburgo, circulando em outras cidades da região ${ }^{10}$, sempre incentivando campanhas a favor de desenvolvimento regional.

Para Ávila (2005), os fundadores do jornal seguiram o mesmo caminho que Assis Chateaubriand e seus Diários Associados, envolvendo-se com a comunidade ${ }^{11}$, pois também aderiram às campanhas pelo desenvolvimento de Novo Hamburgo e região, e

\footnotetext{
${ }^{8}$ Atualmente o Grupo Editorial Sinos publica, também, revistas e jornais voltados para o setor coureiro-calçadista como a revista Lançamentos e Lançamentos Componentes, Couros, Máquinas e Serviços, o Jornal Exclusivo, o Exclusivo On Line, Portal do calçado e da moda, com notícias atualizadas diariamente, além dos jornais VS, Diário de Canoas e $A B C$ Domingo.O grupo ainda mantém um provedor de internet, o Sinosnet, o Sinoscorp de internet corporativa, além de uma emissora de rádio, a $A B C 900$ AM.

${ }_{9}$ Disponível em http://www.gruposinos.com.br/ Acesso em 12/08/2007

${ }^{10}$ Os jornais diários e o jornal e as revistas dirigidos ao setor coureiro-calçadista possuem o invejável índice de cerca de $95 \%$ de sua circulação em assinaturas. Os primeiros somam uma tiragem diária superior a 63.500 exemplares, distribuídos em cerca de 45 municípios, uma área que compreende a Região Metropolitana de Porto Alegre, Vale do Sinos, Vale do Caí, Vale do Paranhana, Serra Turística e parte do Litoral Norte, o que representa 19,29\% da população do Rio Grande do Sul. São mais de 2 milhões de habitantes e uma das maiores rendas per capita do país. Segundo http://www.gruposinos.com.br/

${ }^{11}$ Segundo Ávila (2005) as campanhas nas quais se envolveu Assis Chateaubriand foram: "Dê Asas à Juventude" que promoveria, durante dez anos, a doação de aviões para aeroclubes de todo o Brasil, a Campanha Nacional da Criança, cujo objetivo era diminuir a mortalidade infantil com a construção de postos de saúde em todo o Brasil e a campanha para a criação do Museu de Arte de São Paulo.
}

Cad. de Pesq. Interdisc. em Ci-s. Hum-s., Florianópolis, v.11, n.99, p. 167-185, jul/dez. 2010 
o jornal, desde sua criação, envolveu-se nas campanhas e nas conquistas que a comunidade alcançou.

O autor ressalta três campanhas que tiveram atuação decisiva do jornal: primeiro a campanha em prol da FENAC (Feira Nacional do Calçado), que impulsionou o setor coureiro-calçadista, chamando a atenção do mundo para o Vale do Sinos; depois a campanha pela telefonia, pois a mesma até o início dos anos 60 era via telefonista, e qualquer contato telefônico poderia levar horas; e por fim, a campanha para a implantação de cursos superiores na cidade que acabou levando à criação da ASPEUR (Associação Pró-Ensino Superior em Novo Hamburgo) e, mais tarde, à FEEVALE (Federação de Estabelecimentos de Ensino Superior em Novo Hamburgo).

Atualmente, segundo dados do IVC (Instituto Verificador de Circulação), o Jornal $\mathrm{NH}$ é o maior diário, em termos de assinaturas pagas, do interior do estado do Rio Grande do Sul.

\section{A SITUAÇÃO DE CRISE ELABORADA PELO JORNAL NH}

As reportagens sobre o tema aqui pesquisado não dispõem de um grande espaço textual e, dificilmente, ultrapassam meia página, o que é justificável pela própria natureza do texto jornalístico, o qual é renovado diariamente a partir de informações que são constantemente atualizadas. Por outro lado, há uma constância na temática, apontando para a preocupação do veículo em refletir, nas suas páginas, fatos importantes para a economia regional.

As matérias podem ser encontradas, principalmente, nos cadernos de Economia, Empresas, Empregos e Geral. O mais usado até o ano de 1995 foi o de Economia, a partir daí, o caderno Empresas recebeu maior destaque. Curiosamente, o caderno Empregos portou, entre as matérias pesquisadas, apenas uma veiculação de reportagem relacionada à crise calçadista, que ocorreu no ano de 1995 e intitulou-se "Anúncio atrai 500 sapateiros". Geralmente a presença das matérias ocorria na página direita do jornal, o que remete à importância dada ao assunto 
crise/emprego/desemprego, pois este se constitui lugar privilegiado em um veículo de comunicação impresso.

Também foi possível constatar em meio às reportagens coletadas, a ausência de matérias referentes ao tema desemprego durante o ano de 1996, sendo que a única encontrada traçava um perfil da situação do trabalho no ano anterior (1995). Esta ausência pode ser justificada pelo fato de que houve um aumento de 10,86\% nas exportações brasileiras de calçados naquele ano, o que diminuiu um pouco os efeitos da crise ${ }^{12}$

No período que compreende as décadas de 1980 e 1990 foi intensa a influência do neoliberalismo na economia do país, modelo econômico que apresentava como uma de suas principais características as privatizações do Estado, a desregulamentação dos direitos trabalhistas e a desmontagem do setor produtivo estatal. Esta influência mostrou-se mais clara a partir dos anos 90, com os governos de Fernando Collor de Mello e Fernando Henrique Cardoso, através das políticas monetárias, das privatizações de empresas públicas e do afastamento dos estados do setor produtivo, das flexibilizações e desregulamentações, dentre outras medidas. A consequência foi a alteração nos condicionantes fundamentais do ambiente econômico, o que inspirou um quadro de reestruturação dos mercados e exigiu uma melhor capacitação tecnológica e eficiência produtiva. A mundialização do mercado de capital apresentou resultados complexos no mercado do trabalho, fazendo crescer o mercado informal, as subcontratações e as terceirizações (FIORIN, 2002).

O mesmo autor explica ainda que tal situação ocorreu em quase todos os mercados, os nacionais e os internacionais. Depois de 1990, mas sobretudo depois de 1994, os mercados foram abertos e desregulamentados, e o setor público foi privatizado velozmente em nome da "competitividade global". O Estado foi desmontado, o funcionalismo foi reduzido, mas a mudança do Estado frente aos interesses privados e a proteção de alguns grupos não se alteraram com a abertura comercial e a desregulamentação econômica.

[...] Com relação às promessas relativas aos trabalhadores, os governos neoliberais dos anos 90 promoveram uma ativa desregulamentação do

${ }^{12}$ Segundo dados da Abicalçados, disponíveis em www.abicalcados.com.br. Acesso em 15/09/2009 Cad. de Pesq. Interdisc. em Ci-s. Hum-s., Florianópolis, v.11, n.99, p. 167-185, jul/dez. 2010 
mercado de trabalho, junto com a redução dos direitos trabalhistas, o congelamento dos salários do setor público e uma diminuição da participação salarial, de $45 \%$ para $36 \%$ da renda nacional (FIORIN, 2002, p.211).

A situação acima narrada foi claramente percebida na região em estudo (Vale do Sinos), pois a China, com seus calçados com custos e valores extremamente acessíveis em relação ao produto brasileiro no ano de 1992, foi considerada como a principal causa da queda das exportações brasileiras, gerando um grave momento de crise, o qual resultou em inúmeras falências, causando o aumento do desemprego no país. ${ }^{13}$

De acordo com o presidente executivo da ACI-NH (Associação Comercial e Industrial de Novo Hamburgo), Gilberto Mosmann, a China empregava mão de obra irregular, contratando, inclusive, crianças a partir dos sete anos, em troca de uma remuneração diária e dez dias de férias anuais. As mulheres, ao serem empregadas, deviam se comprometer a não engravidarem, de modo a evitar a ausência no trabalho. Além disso, os empresários chineses encontravam-se isentos dos impostos sobre matérias primas e insumos, o que barateava os custos dos produtos. Esses aspectos influenciavam o baixo preço dos calçados chineses, dificultando a concorrência com o sapato brasileiro, pois na região do Vale do Sinos, os sindicatos já tinham cláusulas trabalhistas vigentes há muito tempo, e os funcionários das empresas recorriam a esses sindicatos a fim de terem seus direitos respeitados, o que, muitas vezes, onerava sua mão-de-obra.

De acordo com consulta aos textos produzidos pelo jornal, em janeiro de 1992, a economia encontrava-se estagnada, enquanto o desemprego era crescente e a inflação alta. O ano de 1991 já havia sido decepcionante para o setor calçadista, as exportações haviam diminuído em considerável grau, várias empresas tinham falido e a mão-de-obra era excedente. A previsão, então, era de que as coisas continuassem desanimadoras.

\footnotetext{
${ }^{13}$ Entre o início da década de 1960 até o final da década 1980, as exportações de calçados do Brasil cresceram de praticamente zero até o nível de 1,8 bilhões de dólares. Neste período, a indústria também contou com um mercado interno protegido de importações. Mas, desde meados dos anos noventa, as exportações brasileiras de calçados estagnaram e, em alguns períodos, o efeito conjunto de baixas tarifas alfandegárias e taxas de câmbio favoráveis permitiram a penetração de importações de calçados no mercado interno. Disponível em http://www.biblioteca.sebrae.com.br/bds/BDS.nsf/AD4E1042AE63ACE68325722C0059C2A8/\$File/NT000 33A8A.pdf
}

Cad. de Pesq. Interdisc. em Ci-s. Hum-s., Florianópolis, v.11, n.99, p. 167-185, jul/dez. 2010 
No dia 3 de janeiro desse mesmo ano (1992), o diretor de assuntos intersindicais afirmava em matéria do Jornal $\mathrm{NH}$ :

O ano de 1991 foi terrível em todos os aspectos. Em 92, pelo menos no campo comercial, as perspectivas não são nada animadoras. A situação se torna mais crítica ainda quando o próprio governo deixa de acreditar no ano que se inicia, passando a apostar em 1993. Nossa torcida é que as previsões catastróficas não se concretizem (Jornal NH, 03/10/1992, p.2).

Essa realidade apresentada explicita a forte concorrência e a ausência de atitudes por parte dos empresários e dos governantes, o que fazia com que a situação econômica se agravasse cada vez mais. O jornal, através da publicação dessa matéria, coloca-se ao lado do setor, pois apresenta ao leitor a fala de um indivíduo próximo aos trabalhadores, ou seja, através da presença de um argumento de autoridade (um sindicalista), dá-se credibilidade à crise. O vocabulário utilizado conduz o leitor a sentimentos de apreensão e preocupação, pois talvez o ano venha a ser "catastrófico", ou seja, desastroso, infeliz, depois de um ano "terrível".

A crise que atingia o país afetou diretamente as indústrias, fazendo com que elas passassem a ter dificuldades para pagar os salários dos trabalhadores. As empresas ainda tentavam resistir ao aumento do desemprego, algumas tomavam como iniciativa decretar férias coletivas para uma grande quantidade de seus funcionários, com o intuito de evitar as demissões. O sindicato dos metalúrgicos de Novo Hamburgo trabalhou, até mesmo, com a hipótese de recorrer à Justiça para conter as demissões, porém, diante do quadro que se constituía na economia regional, essa ação não parecia ser possível. Assim, algumas fábricas, como as duas da falida Sibisa, tiveram de ser leiloadas para possibilitar o pagamento dos seus ex-funcionários; outras nem mesmo assim tiveram condições de arcar com as dívidas. ${ }^{14}$

$\mathrm{O}$ desemprego mostrou-se relacionado à economia nacional. Em pleno governo Collor, o presidente do PT, Luis Inácio Lula da Silva, acusava o governo de aumentar em sete milhões o número de desempregados em dois anos, e causar a mais grave recessão da história do país devido à má estratégia econômica. Lula defendeu, também, a prioridade no pagamento dos ex-funcionários da empresa falida Sibisa, ao

14 Jornal NH, 15/01/1992, p.5

Cad. de Pesq. Interdisc. em Ci-s. Hum-s., Florianópolis, v.11, n.99, p. 167-185, jul/dez. 2010 
invés de saldar dívidas contraídas em agências bancárias, segundo informação retirada do Jornal NH do dia 14 de fevereiro de 1992.

No tocante ao estado gaúcho, o aumento do desemprego em Porto Alegre atingiu o índice de $191,23 \%$ em relação ao ano de 1991. Como consequência da elevação, ocorreu o aumento de solicitação de seguro desemprego ao Sistema Nacional de Empregos. ${ }^{15}$

A partir de março de 1992, constata-se a modificação do perfil do desempregado, de acordo com o Jornal $\mathrm{NH}$. Enquanto que na década de 70 , mais da metade dos desempregados eram formados por jovens sem experiência, nos anos 90 , uma análise construída pela Carta de Conjuntura (um boletim da Fundação de Economia e Estatística - FEE do governo gaúcho) afirma que o desemprego atingiu 94,21\% dos trabalhadores que já possuíam experiência anterior. Além do mais, o desemprego continuou crescente. Houve, nesse momento, a opção, por parte dos empresários, em elegerem a terceirização, ao invés da contratação efetiva dos funcionários, como a situação mais adequada no momento. ${ }^{16}$

Essa afirmação pode ser reforçada pelas palavras de Marcio Pochmann (2001),

O princípio da demissão atingiu em maior escala parte dos trabalhadores com maior tempo de serviço na mesma empresa. Enquanto os empregados com até um ano na mesma empresa foram reduzidos em quase $46 \%$, os empregados com três a dez anos de casa tiveram cerca de $66 \%$ dos postos de trabalhos destruídos. Somente os empregados com mais de dez anos de tempo de serviço na mesma empresa foram os menos atingidos pelo fenômeno da demissão (POCHMANN, 2001, p. 181).

Após o fechamento de cinco empresas, desde o início do ano de 1992, o Sindicato dos Trabalhadores na Indústria de Calçado organizou passeatas contra o desemprego, ação que se repetiu, também, no mês de abril, na cidade de Sapiranga ${ }^{17}$, de acordo com o Jornal NH, de abril de 1992.

Nos seis anos correspondentes ao período de 1986 a 1992, os profissionais da categoria do calçado, que chegavam ao expressivo número de 35.000 empregados em Novo Hamburgo, passaram a ser 17.000, e, ao mesmo tempo, existiam 8.000 desempregados no setor. Os empresários industriais alegavam a queda do mercado

\footnotetext{
15 Jornal NH, 20/01/1992, p.3

16 Jornal NH, 14 e 15/03/1992, p.8

17 Sapiranga é uma cidade localizada no Vale do Rio dos Sinos, distante $20 \mathrm{~km}$ de Novo Hamburgo.
}

Cad. de Pesq. Interdisc. em Ci-s. Hum-s., Florianópolis, v.11, n.99, p. 167-185, jul/dez. 2010 
interno em relação aos pedidos de sapatos e acessórios em couro, como justificativa para o fechamento das fábricas e as demissões em massa. Outros sindicalistas culpavam, também, a troca da mão de obra humana pelas máquinas, decorrente do desenvolvimento tecnológico muito presente nesse período. ${ }^{18}$

Devido a tais fatores, algumas empresas admitiam grande número de empregados sem direitos trabalhistas, ou efetuavam contratações por tempo determinado, alcançando uma rotatividade média de $10 \%$ a $15 \%$ em seus quadros funcionais, de acordo com reportagem do Jornal $\mathrm{NH}$, do dia 3 de janeiro de 1992. Essa situação não era elogiada nem criticada pelo jornal, simplesmente anunciada, o que pode corroborar com o posicionamento de não confronto com os empresários por parte do discurso jornalístico.

Além disto, nesse período, observava-se que $24 \%$ dos empregados tinham menos de 18 anos, e a justificativa usada para esta situação foi de que os menores eram a opção da família que vivia em meio à crise econômica no Brasil. Tornava-se evidente a preocupação com o emprego de menores, especialmente aqueles que trabalhavam com colagem de calçados, posto que o Sindicato dos Sapateiros, frente à situação de crise, defendia o emprego de menores, mas impunha a proibição do trabalho com cola. Em plena luta pelo aumento salarial, os calçadistas visavam a alcançar 2,5 salários mínimos como piso, e aguardavam propostas do governo. Depois de muitas discussões, protestos e ameaças, os calçadistas acabaram por aceitar o acréscimo salarial e rejeitaram a greve. ${ }^{19}$

Com a economia em ritmo extremamente lento, poucos empregos eram oferecidos, porém, apesar da crise, a abertura da Indústria Ferst, no local de outra empresa falida, gerou 500 novos empregos em Campo Bom ${ }^{20}$. Empresários desta empresa, na época, sugeriram a união de entidades empresariais em busca de uma saída junto ao governo ${ }^{21}$, no entanto, ao que parece, não houve avanços, pois nada foi divulgado no periódico. Outra preocupação apresentada pela indústria Ferst, dizia respeito à melhoria da qualidade dos calçados lá produzidos e, para tanto, o diretor

\footnotetext{
18 Jornal NH, 01/05/1992, p.34

19 Jornal NH, 19/05/1992, p.3

${ }^{20}$ Campo Bom faz parte da Região do Vale dos Sinos, distante $5 \mathrm{~km}$ de Novo Hamburgo.

21 Jornal NH, 21/05/1992, p.10
}

Cad. de Pesq. Interdisc. em Ci-s. Hum-s., Florianópolis, v.11, n.99, p. 167-185, jul/dez. 2010 
presidente da empresa, Lair Antonio Ferst, afirmou a intenção de cursos permanentes de aperfeiçoamento dos funcionários e, além do salário estipulado pelo mercado, uma comissão prêmio para aquelas empresas que investissem na qualidade dos produtos. "Nós adotamos o salário do mercado, que é um salário que, reconheço, é muito baixo, mas esperamos recuperar com prêmio produtividade a ser definido junto aos empregados. [...] Se não pagarmos bem, não vamos ter bom produto. Isso evitará a alta rotatividade", disse o empresário em reportagem do Jornal $\mathrm{NH}$ do dia 21 de maio de 1992.

Ferst também contratou a Consulting, de Novo Hamburgo, para garantir as exigências de qualidade européias, uma vez que, se a matéria prima não passasse no controle de qualidade, seria recusada pelos importadores, o que, mais uma vez, poderia dificultar as exportações da região. O jornal mostra, então, um empresário que tem preocupações, não só com a produtividade de sua empresa, mas também com seus funcionários, podendo, talvez, servir como exemplo para outros empresários, ou enfatizando a necessidade de mudanças na administração de certas empresas.

No mês de junho, enquanto os desempregados alcançaram o número de 89.000 na região metropolitana, algumas empresas adotaram a hora extra de trabalho para aumentar a produtividade; o que foi considerado um absurdo diante do índice de desemprego. O sindicalista Cesar Hartmann mostrou-se contra a decisão e a considerou "vergonhosa [...] Essa liberdade de escolha para realizar horas-extras, quando há um grande exército de desempregados", afirmação na reportagem do Jornal NH do dia 09 de junho de 1992.

Segundo o presidente da FIERGS, mais de 50 mil pessoas perderam seu emprego no decorrer de 1992. A indústria gaúcha fechou o ano com 1,8\% de crescimento no setor, o que propiciava ao presidente da Associação Brasileira de Exportação de Calçados e Afins apostar no crescimento das exportações para o próximo ano (1993). Entretanto, nos últimos três meses do ano foram cinco mil vagas preenchidas nas empresas, contrariando as expectativas anteriores.

No ano de 1993, constatou-se a demanda de mão de obra e houve o cancelamento das férias coletivas em virtude do crescimento das exportações. Nos 
primeiros seis dias desse ano, foram contratados 150 trabalhadores e algumas empresas chegaram a aumentar $57,14 \%$ a carga horária dos funcionários. A empresa Irmãos Muller, por exemplo, exportava para a Europa e para os Estados Unidos 5.800 dos 7.000 pares/dia produzidos, e 1.200 pares para outras partes do mundo. Essa situação ocasionou grandes filas de pedido de emprego, o que gerou certa esperança para os profissionais da área, os quais vinham sofrendo pela falta de emprego nas empresas do Vale. ${ }^{22}$

Tendo em vista a significativa melhora na economia nacional, o sindicalista Carlos Gilberto Koch, como muitos outros empresários, acreditava que a tendência era reduzir o número de desempregados. Referindo-se aos atuais 10.000 desempregados na região, Koch afirmou que "vivemos um período altamente recessivo durante o governo Collor. O achatamento salarial foi violento e atingiu a todos. Agora, aos poucos, as coisas começam a melhorar, e a tendência é este número cair gradativamente" (Jornal NH de 19 de janeiro de 1993). Verifica-se, então, o otimismo sendo noticiado pelo jornal, mesmo que o final da crise ainda não houvesse chegado.

No entanto, a partir do mês de maio, devido à greve dos trabalhadores do transporte rodoviário e às paralisações dos fiscais federais nos portos e aeroportos, as exportações foram novamente afetadas. Alguns empresários culparam o governo federal pelo caos estabelecido e temiam o prejuízo de US\$ 500 milhões em consequência dos produtos retidos nos portos e aeroportos, sendo que 2 milhões de pares deixaram de ser exportados naquele mês. ${ }^{23}$

Contraditoriamente ao revelado até então, no mês de agosto, o salário mensal dos trabalhadores mostrou-se insuficiente para o sustento de uma família de quatro pessoas. Procurando reverter essa situação, representantes dos sapateiros de Novo Hamburgo anunciaram a criação da federação sindical, que poderia trazer vantagens para os trabalhadores no que diz respeito a uma data base unificada e a conscientização dos direitos sindicais. Ainda no mesmo mês, estudos mostraram a queda dos salários em todos os setores, sendo que o aumento salarial do setor coureiro-calçadista foi abaixo da inflação.

\footnotetext{
22 Jornal $\mathrm{NH}, 07 / 01 / 1993$, p.10

${ }^{23}$ Jornal NH, 15 e 16/05/1993, p.3
}

Cad. de Pesq. Interdisc. em Ci-s. Hum-s., Florianópolis, v.11, n.99, p. 167-185, jul/dez. 2010 
Semelhante ao já ocorrido em outras fábricas, motivados pelo atraso nos pagamentos, 780 funcionários paralisaram os serviços em forma de protesto, alegando que só voltariam ao trabalho depois de efetivado os devidos pagamentos, o que resultou em 200 demissões. ${ }^{24}$

No mesmo período, cursos profissionalizantes eram oferecidos pelo sindicato e pelo SINE (Sistema Nacional de Empregos). Essas ações tinham como preocupação a formação profissional dos desempregados do setor e intencionavam melhorar a qualidade dos produtos brasileiros, o que era visto como um empecilho ao aumento das vendas.

Com a baixa das exportações, a crise tornou-se mais aguda. Enquanto a China exportava 60,20\% de calçados para os EUA, em 1993 o Brasil forneceu apenas 9,17\% do total calçadista para aquele país. Ainda em relação ao comércio internacional, os industriais chilenos, preocupados com o desempenho brasileiro quanto às vendas para o seu país, acusavam o Brasil de concorrência desleal na área calçadista. Eles argumentavam que as indústrias brasileiras eram subsidiadas e, em consequência do alto volume de importados, encontravam-se em situação delicada. O presidente chileno desejava, ainda, solicitar ao governo uma barreira para o calçado brasileiro. ${ }^{25}$

O ano de 1994 foi marcado pela implantação do Plano Real e pela contínua queda das exportações que aumentou o número de demissões de maneira significativa. Logo na fase inicial do ano, as previsões já eram de dez mil demissões, e a solução almejada pelos empresários foi a tentativa de redução do preço do calçado a ser exportado, em torno de dois a três dólares.

Segundo Costa (2004),

No que se refere à fase de dificuldades, a década de 1990 trouxe uma mudança no ambiente competitivo para o setor calçadista brasileiro. A abertura da economia no início daquele período, com queda das barreiras tarifárias e nãotarifárias, e a política de estabilização do Plano Real de julho de1994, com a valorização do câmbio, levaram a um período de constrangimentos para a indústria brasileira de calçados. Esses fatores geraram uma perda de competitividade dos calçados, tanto no mercado externo quanto no interno (COSTA, 2004, p.17).

\footnotetext{
${ }^{24}$ Jornal $\mathrm{NH}, 28 / 12 / 1993$, p. 6

${ }^{25}$ Jornal NH, 17/01/1994, p.13
}

Cad. de Pesq. Interdisc. em Ci-s. Hum-s., Florianópolis, v.11, n.99, p. 167-185, jul/dez. 2010 
No ano de 1995 a crise fez aumentar ainda mais o percentual de desemprego na região. Entre maio e junho desse ano, 450 funcionários de pequenas e médias empresas foram dispensados de seus cargos na cidade de Parobé $^{26}$. As poucas empresas que ainda resistiam à crise trataram de diminuir as cargas horárias para evitar demissões em massa. Os trabalhadores desocupados, que para cá haviam migrado em busca de uma vida melhor na região do calçado, sentiam-se arrependidos e, em meio a tantas dificuldades. Em virtude disso, deparavam-se com o desejo de retornar às suas cidades de origem e cultivavam certo sentimento de derrota, conforme observamos na matéria intitulada "A vida sem um salário mensal" do jornal $\mathrm{NH}$ de 11/05/1995.

O município de Dois Irmãos ${ }^{27}$ foi um dos menos atingidos pela crise do emprego. Apesar de o número de empregos diretos do setor calçadista ter caído 4,64\%, comparado ao mês de abril do ano anterior, parte deste percentual foi absorvido pelas fábricas de espuma, gerando o aumento do número de empregos terceirizados e resultando na elevação de $0,54 \%$ no nível de emprego em relação ao mês anterior. $O$ presidente do Sindicato da Indústria do Calçado da cidade, Ricardo Wirth, destacou que as indústrias de Dois Irmãos possuíam rigidez e solidez econômica, de forma que se mostravam aptas a enfrentarem situações difíceis. ${ }^{28}$

Outras cidades do Vale do Sinos, que tinham pequenas e médias empresas, também se encontravam em situação igualmente preocupante, como as fábricas CDM (de Novo Hamburgo) e a Ferst (de Campo Bom), que foram incapazes de cumprir os pagamentos contratuais. Elas usaram como moeda de pagamento das rescisões dos seus funcionários os próprios calçados fabricados por eles. Assim, os sapateiros que aceitaram os calçados ao invés do dinheiro da rescisão, depararam-se com as dificuldades de venda do material e permaneceram com muitos pares desses sapatos "encalhados" em casa, o que não resolveu seu problema. Outras cidades como São Leopoldo viam-se em posição privilegiada em relação às demais, pois municípios como Estância Velha, Novo Hamburgo e Taquara foram os que apresentaram maior índice de

\footnotetext{
${ }^{26}$ Parobé faz parte do Vale do Paranhama e fica distante $35 \mathrm{~km}$ de Novo Hamburgo.

${ }_{28}^{27}$ Cidade do Vale do Sinos, distante $18 \mathrm{~km}$ de Novo Hamburgo.

${ }^{28}$ Jornal NH, 09/06/1995, p.4
} 
desemprego, sendo o primeiro com $39 \%$ e os outros dois com $38 \%{ }^{29}$. O que sofreu menor queda no nível de emprego foi São Leopoldo, com 13\%, de acordo com matéria publicada no Jornal $\mathrm{NH}$, do dia 12 de maio de 1995.

Esperançosos, 500 sapateiros amanheceram nas portas dos Calçados Diagi, uma empresa nova que se instalou na cidade de Novo Hamburgo e ofereceu 80 vagas. A indústria não precisou mais do que um simples cartaz anexado à sua porta para atrair um grande número de candidatos e a notícia se espalhou apenas no boca a boca. Muitos trabalhadores, sem emprego, já haviam adquirido o hábito de passar nas empresas para receber notícias de possibilidade de emprego.

No decorrer desse ano, foi criado o PROGER (Programa de Geração de Emprego e Renda), que recolheu projetos que deveriam ser avaliados pela $\mathrm{ACl}-\mathrm{NH}$. Dos recursos repassados através do Programa, $70 \%$ objetivava ser aplicado em investimentos, e o restante destinava-se a financiar um capital de giro com juros de $4,8 \%$ ao ano.

$\mathrm{O}$ ano encerrou com dois fatores sendo apontados como causas do elevado crescimento do desemprego. O primeiro aplicou-se à política de estabilização do governo, através da contenção do crédito e à defasagem cambial, que reduziu a atividade econômica do país. E, o segundo, referiu-se às mudanças na economia, com a globalização e a entrada dos importados com preços menores, o que resultou na fragilização das empresas nacionais.

Em agosto de 1997, beneficiada pelo FUNDOPEM (Fundação Operação Empresa) municipal a empresa Zenglein instalou-se na locação do falido Calçados Centenário, gerando 500 vagas para o mês seguinte. O projeto FUNDOPEM caracterizou-se como incentivo para empresas já fixadas ou que quisessem estabelecer-se em Novo Hamburgo, com o objetivo de atrair mais empresas para 0 município e produzir mais empregos. Se a lei fosse aprovada, empresas calçadistas, como a Beira Rio (de Igrejinha) e a Azaléia (de Parobé), intencionariam abrir sede na cidade. ${ }^{30}$

\footnotetext{
${ }^{29}$ A título de comparação, a cidade de São Paulo apresentou um índice de $35 \%$ de desempregados nesse período.

${ }^{30}$ Jornal NH, 19/08/1997, p.6

Cad. de Pesq. Interdisc. em Ci-s. Hum-s., Florianópolis, v.11, n.99, p. 167-185, jul/dez. 2010
} 
No início de 1998, os governantes mostravam-se extremamente preocupados com a crise que vinha se alastrando cada vez mais e atingindo, também, os profissionais liberais que não possuíam, segundo eles mesmos, mais condições de pagar os impostos. O desemprego continuava crescente e a fome aumentava. Diante dessa situação, vereadores elaboraram um projeto de lei que criava o Conselho Municipal Pró-Geração de Emprego e Renda (COMGER) e instituíram o Fundo de PróGeração de Emprego e Renda (FUNGER).

O índice de desemprego era o segundo maior desde 1984, ficando na faixa de $8,18 \%$. Neste ano, investiu-se em palestras e estudos que avaliavam o fim do emprego e as possibilidades de reconstituição, através do programa de Qualidade Total $^{31}$ e do incentivo a novos empreendedores. No mês de junho, pesquisas do IBGE constatavam queda na taxa de desemprego, a qual passou para $7,90 \%$, mostrando que o desemprego foi mais intenso entre as pessoas da faixa etária de 18 e 24 anos e para aquelas entre 25 e 39 anos de idade. No final do mês de agosto, a taxa voltou a subir, ao mesmo tempo em que aumentou, também, o tempo de procura de emprego em todos os estados, exceto em São Paulo. Tais informações geraram atos públicos contra o desemprego em todo o país.

\section{CONSIDERAÇÕES FINAIS}

As matérias publicadas no jornal $\mathrm{NH}$ permitem pensarmos acerca do contexto histórico da região do Vale do Rio dos Sinos, e a crise que abalou o setor Coureirocalçadista, como "arquivos do cotidiano" as matérias investigadas permitem pensarmos acerca da complexidade de uma crise regional que estava diretamente relacionada as mudanças nacionais e internacionais. Percebe-se a preocupação, por parte do veículo de comunicação, de difundir dados e informações que possibilitassem o entendimento da crise e de sua amplitude, bem como as novas perspectivas econômicas mundiais. Também se percebe uma escrita voltada à sensibilização de autoridades em relação às

\footnotetext{
${ }^{31}$ Conjunto de programas, ferramentas e métodos aplicados no controle do processo de produção das empresas, para obter bens e serviços pelo menor custo e melhor qualidade, objetivando atender as exigências e a satisfação dos clientes.
}

Cad. de Pesq. Interdisc. em Ci-s. Hum-s., Florianópolis, v.11, n.99, p. 167-185, jul/dez. 2010 
consequências da crise, como fechamento de empresas e o aumento do desemprego na região.

Devido a sua gravidade, a crise afetou não apenas o setor calçadista, mas também se verificou sua presença em várias outras áreas, prejudicando toda a região. Tais circunstâncias foram, diariamente, transmitidas à sociedade do Vale do Sinos através das reportagens editadas pelo Jornal $\mathrm{NH}$, no formato de um jornalismo informativo, o qual construiu determinada visão da crise, reforçando a experiência vivenciada pelos leitores e passando informações a respeito das decisões governamentais.

As transformações que ocorreram no âmbito econômico e social durante o período de 1992 a 1998, foram apresentadas à população do Vale do Sinos, entre outras formas, através dos editoriais do jornal $\mathrm{NH}$, possibilitando a formação de uma opinião por parte do leitor.

Tendo como causa principal a forte concorrência, os elevados valores de insumos, altos impostos e a má qualidade do calçado e do couro nacional, sem dúvida a crise ocorrida entre o período de 1992/1998 foi a mais grave já enfrentada pelo setor coureiro-calçadista da região.

Definido como um período de pior desempenho econômico no Brasil, o espaço de tempo estudado foi caracterizado por uma acentuada redução do nível de emprego, pelas mudanças no perfil ocupacional e pelas lutas salariais. No setor produtivo estatal, destacou-se a adoção de novos programas de gestão de mão-de-obra, a fim da intensificação do trabalho.

Neste sentido, o jornal $\mathrm{NH}$ configura uma importante fonte para a pesquisa histórica, especialmente para aquelas que almejam discutir elementos históricos que envolvem as comunidades que formam a região do Vale do Rio dos Sinos. Longe de ousarmos percebê-lo como "verdade absoluta", pensamos nas matérias elencadas do $\mathrm{NH}$ como instigadoras de interpretações e como uma fonte que possibilita refletirmos sobre a construção das diferentes representações elaboradas sobre o setor coureirocalçadista. 


\section{REFERÊNCIAS}

ABICALÇADOS. Disponível em: <wwww.abicalcados.com.br>. Acesso em 15 set. 2009.

ÁVILA, J. C.R. O papel do Jornal NH no desenvolvimento econômico regional. ENCONTRO NACIONAL DA REDE ALFREDO DE CARVALHO, 3, 2005, Novo Hamburgo. Anais... Centro Universitário Feevale: Novo Hamburgo, 2005. CD-ROM.

BACKZO, B. A Imaginação Social. In: ROMANO, R. Enciclopédia Eunaudi. v.5.Lisboa: Imprensa Nacional, 1985. p. 296-331.

BARDIN, L. Análise de conteúdo. Lisboa: Edições 70, 1995.

BOURDIEU, P. O poder simbólico. Rio de Janeiro: Bertrand Brasil, 2002.

CAPELATO, M.H. A imprensa na história do Brasil. São Paulo: Contexto/EDUSP, 1988.

CHARTIER, R. O mundo como representação. Estudos Avançados, São Paulo, v.5, n.11, p.173-191, jan./abr.1991.

COSTA, A. B. \& PASSOS, M, C. (orgs.) A indústria calçadista no Rio Grande do Sul. São Leopoldo: Editora Unisinos, 2004.

ELMIR, C. P. As armadilhas do jornal: algumas considerações metodológicas de seu uso para a pesquisa histórica. Cadernos do PPG em História, UFRGS, n.13, p.19-29, dez. 1995.

ESPIG, M.J. O uso da fonte jornalística no trabalho historiográfico: o caso do Contestado. Estudos Ibero-Americanos, Porto Alegre, v.XXIV, n.2, p.269-289, dez.1998.

FIORI, J. L. 60 lições dos 90: uma década de neoliberalismo. 2 ed. Rio de Janeiro: Record, 2002. 
GEERTZ, C. A interpretação das culturas. Rio de Janeiro:RPC, 1989.

GRUPO EDITORIAL SINOS. Apresenta dados e informações a respeito do Jornal $\mathrm{NH}$ e outros veículos de comunicação de propriedade do grupo. Disponível em: http://www.gruposinos.com.br/. Acesso em: 12 ago. 2007.

JORNAL NH. Novo Hamburgo/RS, jan.1992 - ago.1997.

MORAES, R. Análise de conteúdo. Revista Educação, Porto Alegre, ano. 21, n.37, p.732, mar. 1999.

ORLANDI, E. P. As formas do silêncio: no movimento dos sentidos. São Paulo: UNICAMP, 1993.

POCHMANN, M. A década dos mitos. São Paulo, Contexto, 2001.

Artigo:

Recebido em: 27/10/2010

Aceito em: 29/10/2010 